\title{
Actinomyces neuii subsp. neuii Isolated from Perineal Abscess; Case Report
}

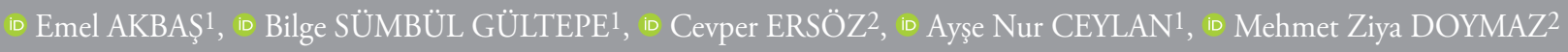 \\ ${ }^{1}$ Bezmialem Vakıf University Faculty of Medicine, Department of Medical Microbiology, İstanbul, Turkey \\ 2Bezmialem Vakıf University Faculty of Medicine, Department of Urology, İstanbul, Turkey
}

\begin{abstract}
Actinomyces are gram positive bacilli which generally colonize in mouth, colon and vagina. The members of genus Actinomyces are facultative anaerobic or microaerophilic organisms and have a branching flamentous structure. They cause classical actinomycosis. Among the Actinomyces species; $A$. israelii, $A$. viscosus, $A$. naeslundii, $A$. odontolyticus, $A$. bovis and $A$. neuii are the mostly isolated organisms from clinical cases. A rarely encountered member of this group, Actinomyces neuii does not show branching and is catalase and CAMP positive and is a coryneform shaped bacillus. Although Actinomyces is mostly found as contaminating organism, in some cases it is reported as a pathogen. Actinomyces neuii has been reported in chorioamnionitis, neonatal sepsis, vertebral osteomyelitis, cervical lymphadenitis, breast abscess, fatal bacteremia and postoperative endophthalmitis. In our case, A. neuii was isolated from a perineal abcess and it was not previously reported. In our case, Actinomyces neuii was identified by commercial identification systems. For this purpose; VITEK MS and VITEK 2 Compact (both by bioMérieux, France) were used in the clinical microbiology laboratory and then this identification was confirmed as the Actinomyces neuii subsp. neuii by the $16 \mathrm{~S}$ rRNA sequencing. Also, the positivity of CAMP was demonstrated in the laboratory. As in the cases of other actinomycosis, the treatment of the abcess caused by the Actinomyces neuii is through the surgical debridement. The antimicrobial susceptibility testing is not performed since the organism is reported to be susceptibile to common antibiotics. Beta lactam antibiotics are acknowledged as the proper selection for antibiotic treatment.
\end{abstract}

Keywords: Actinomyces neuii subsp. neuii, perineal abscess, Actinomyces

\section{Introduction}

As member of the oral flora, actinomyces are organically anaerobic or microaerophilic and sporless microorganisms. These bacteria with difteroid basil morphology that do not react to acid-fast stain and do not show motility are gram positive bacteria and show branching (1). A. israelii, $A$. viscosus, $A$. naeslundii, $A$. odontolyticus, $A$. bovis and $A$. neuii are species isolated from many clinical cases among Actinomyces species.

Actinomyces neuii is aerobic and catalase positive member of this family. A. neuii was involved in the CDC coryneform group 1 bacteria until 1994. In a study by Funke et al. (2) on the metabolic and cellular fatty acid pattern of bacterium and $16 \mathrm{~S}$ ribosomal
RNA (rRNA) sequence; bacteria were defined as Actinomyces neuii subsp. neuii and Actinomyces neuii subsp. Anitratus.

A. neuii was previously isolated as an infection agent in soft tissue in a study conducted by Gomez-Garces et al. (3). In our study, A.neuii was first isolated from a perineal abscess sample in our country.

\section{Case Report}

Fifty-two-year-old male patient was admitted to urology outpatient clinic with tenderness and swelling in the groin. He had scrotal lesions for 20 years and he said that these lesions merged and pain increased for one week. In addition, it was learned that he

Address for Correspondence: Bilge Sümbül GÜLTEPE, Bezmialem Vakıf University Faculty of Medicine, Department of Medical Microbiology, İstanbul, Turkey

Phone: +90 2124531800 E-posta: bilgesumbul@hotmail.com ORCID ID: orcid.org/0002-8768-3777 
had type 2 diabetes mellitus, which was not regulated for 5 years and he was followed up with hypertension. Physical examination revealed a fever of $37.2^{\circ} \mathrm{C}$ and a swelling in $4 \times 4 \mathrm{~cm}$ dimensions, stretching from perineum to scrotum, giving perineal induction and suggesting abscess. The number of leukocytes in the complete blood count was $18.5 \times 10^{3} / \mathrm{uL}$, CRP was $4.36 \mathrm{mg} / \mathrm{dL}(<0.5)$ and glucose was $4+$ in complete urine examination. The surface tissue ultrasonography revealed a heterogeneous hypoechoic collection with dense content and thickening of subcutaneous tissue which was $35 \times 16 \mathrm{~mm}$ in diameter, partially extended from the posterior of the scrotum to the perineum, and had debris and septations within the thick wall. The contents of the $30 \mathrm{cc}$ abscess were completely drained with $1 \mathrm{~cm}$ incision from the apse surface and sent to the microbiology laboratory. The patient was hospitalized and started empirically intravenous ceftriaxone $2 \times 1 \mathrm{~g} /$ day and gentamicin $3 \times 3 \mathrm{mg} / \mathrm{kg} /$ day. In addition, antidiabetic treatment for blood sugar regulation was started. In the first follow-up day, mild serous drainage was observed and no collection was observed in the abscess area of the patient with flow in the incisions during the day. Control leukocyte count was $11.8 \times 10^{3} /$

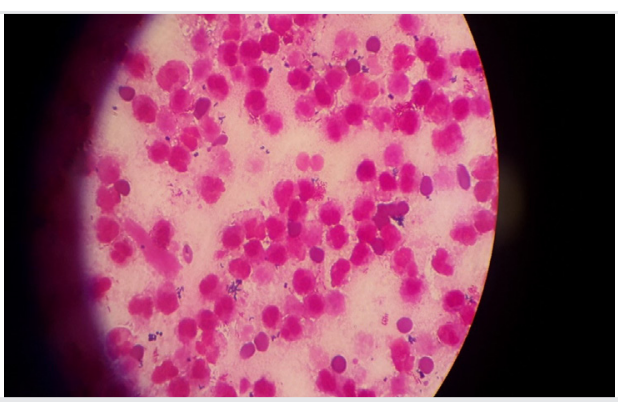

Figure 1. Direct microscopic examination from the abscess sample sent to the laboratory

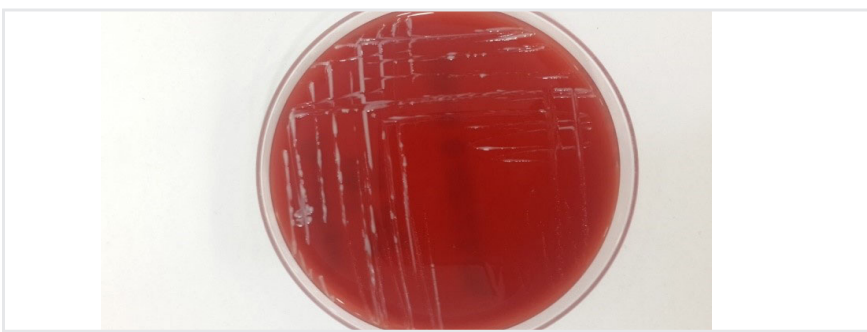

Figure 2. Colony image of abscess sample sent to laboratory and incubated in $5 \%$ sheep blood agar at $350 \mathrm{C}$ for 48 hours

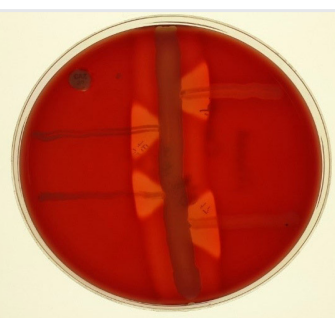

Figure 3. CAMP test performed with $A$. neuii and Staphylococcus aureus
$\mathrm{uL}$ and CRP was $0.92 \mathrm{mg} / \mathrm{dL}$. Due to improvement of clinical symptoms, he was discharged with $2^{\text {nd }}$ generation cephalosporin on the $3^{\text {rd }}$ day. On the $1^{\text {st }}$ week control, the number of leukocytes and CRP levels were normal and no perineal collection was detected and antibiotic therapy was terminated. Also perineal region examination was evaluated as normal on $1^{\text {st }}$ and $2^{\text {nd }}$ month controls. In the Clinical Microbiology Laboratory, gram positive coryneform bacilli and leukocyte were found in direct microscopic examination of perineal abscess sample (Figure 1). Simultaneously, cultures were prepared at 5\% sheep blood agar (Becton Dickinson, USA), MacConkey Agar (Becton Dickinson, USA) and chocolate agar (Becton Dickinson, USA) and they were incubated in incubator with $\mathrm{CO}_{2}$ at $35^{\circ} \mathrm{C}$ for 72 hours. In the culture examination, round colonies of 0.5-1.5 mm diameter in white color which were opaque, smooth-shaped and non-hemolytic were produced (Figure 2). Microscopic examination of these colonies showed grampositive, non-branching coryneform-shaped, catalase-positive, inactive and sporeless bacilli. Breeding colonies were identified with conventional methods and Vitek MS (bioMérieux, France) system as Actinomyces neuii. At the same time, with 16s rRNA analysis (Sentegen Biotechnology, Ankara), Actinomyces neuii subsp. neuii was confirmed. In addition, Staphylococcus aureus ATCC 29213 strain and CAMP formation were investigated and a relationship was found between them (Figure 3).

Since $A$. neuii is sensitive to many antibiotics, antimicrobial susceptibility tests are not performed and $\beta$ lactam antibiotics are considered appropriate. In this case, a similar treatment regimen was given and an uncomplicated recovery was observed.

\section{Discussion}

Actinomyces species have been isolated from clinical specimens such as blood, wound, bone, abscess, bronchial wash, gallbladder fluid, pleural fluid and urine (1). Although they generally show better reproduction in anaerobic conditions, some species such as $A$.neuii can be isolated under aerobic conditions and 5-10\% $\mathrm{CO} 2$ conditions.

A. neuii is catalase and CAMP positive and coryneform-shaped basil. These features separate it from other Actinomyces species. Also, $A$. neuii has a short basil appearance that does not show branching, unlike other species (2-4). It fermentates glucose, maltose, sucrose, mannitol, lactose, mannose, trehalose and xylose. Negative catalase reaction of $A$. neuii has also been reported. Brunner et al. (5) defined catalase negative $A$. neuii in a patient with breast prosthesis infection.

Actinomyces neuii, isolated from scrotal abscess sample, is a very rare microorganism seen in the laboratory as an infection agent and was not reported as agent in our country before. This case was presented because $A$. neuii is a clinically important and rare microorganism. In the literature, it was reported as pathogenic microorganism in different clinical specimens. For example, Mann et al. (6) isolated $A$. neuii as agent in a patient with neonatal sepsis and chorioamnionitis. In various studies, $A$. neuii was reported to cause endoftalmit, bacteremia, endocarditis, 
pericarditis, osteomyelitis and prostatitis $(7,8)$. Lacoste et al. (9) isolated A.neuii in breast abscess.

Surgical debridement is recommended in the treatment of soft tissue infections caused by Actinomyces species. It is sensitive to many antibiotics and $\beta$-lactam antibiotics is primarily preferred (10).

A.neuii, isolated from perineal abscess as a pathogen agent, which was a rarely seen agent, was reported here. It is important for the prognosis to determine the appropriate treatment approach with the correct identification of species with new microbiological methods. Isolation of A.neuii for the first time in our country adds specificity to the study.

\section{Ethics}

Informed Consent: A consent form was completed by all participants.

Peer-review: Externally peer rewieved.

\section{Authorship Contributions}

Concept: B.S.G., E.A., A.C., C.E., M.Z.D., Design: B.S.G., E.A., A.C., C.E., M.Z.D., Data Collection or Processing: B.S.G.,E.A., A.C., Analysis or Interpretation: B.S.G., E.A., A.C., Literature Search: B.S.G., E.A., C.E., Writing: B.S.G., E.A., C.E.

Conflict of Interest: No conflict of interest was declared by the authors.

Financial Disclosure: The authors declared that this study received no financial support.

\section{References}

1. Winn WC. Koneman's color atlas and textbook of diagnostic microbiology: Lippincott williams \& wilkins; 2006.
2. Funke G, Stubbs S, Vongraevenitz A, Collins MD. Assignment of Human-Derived Cdc Group-1 Coryneform Bacteria and Cdc Group 1-Like Coryneform Bacteria to the Genus Actinomyces as Actinomyces-Neuii Subsp Neuii Sp-Nov Subsp Nov and Actinomyces-Neuii Subsp Anitratus Subsp Nov. Int J Syst Bacteriol 1994;44:167-71.

3. Clarridge JE 3rd, Zhang Q. Genotypic diversity of clinical Actinomyces species: phenotype, source, and disease correlation among genospecies. J Clin Microbiol 2002;40:3442-8.

4. Funke G, Lucchini GM, Pfyffer GE, Marchiani M, von Graevenitz A. Characteristics of CDC group 1 and group 1-like coryneform bacteria isolated from clinical specimens. J Clin Microbiol 1993;31:2907-12.

5. Brunner S, Graf S, Riegel P, Altwegg M. Catalase-negative Actinomyces neuii subsp neuii isolated from an infected mammary prosthesis. Int J Med Microbiol 2000;290:285-7.

6. Mann C, Dertinger S, Hartmann G, Schurz R, Simma B. Actinomyces neuii and neonatal sepsis. Infection 2002;30:178-80.

7. Garelick JM, Khodabakhsh AJ, Josephberg RG. Acute postoperative Endophthalmitis caused by Actinomyces neuii. Am J Ophthalmol 2002;133:145-7.

8. von Graevenitz A. Actinomyces neuii: review of an unusual infectious agent. Infection 2011;39:97-100.

9. Lacoste C, Escande MC, Jammet P, Nos C. Breast Actinomyces neuii abscess simulating primary malignancy: a case diagnosed by fineneedle aspiration. Diagn Cytopathol 2009;37:311-2.

10. Zelyas N, Gee S, Nilsson B, Bennett T, Rennie R. Infections Caused by Actinomyces neuii: A Case Series and Review of an Unusual Bacterium. Can J Infect Dis Med Microbiol 2016;2016:6017605. 